JOURNAL OF

SYNCHROTRON

RADIATION

ISSN 1600-5775

Received 27 August 2021

Accepted 5 December 2021

Edited by K. Kvashnina, ESRF - The European Synchrotron, France

Keywords: small-angle X-ray scattering; actinide; $\mathrm{ThO}_{2} ;$ crystallites.

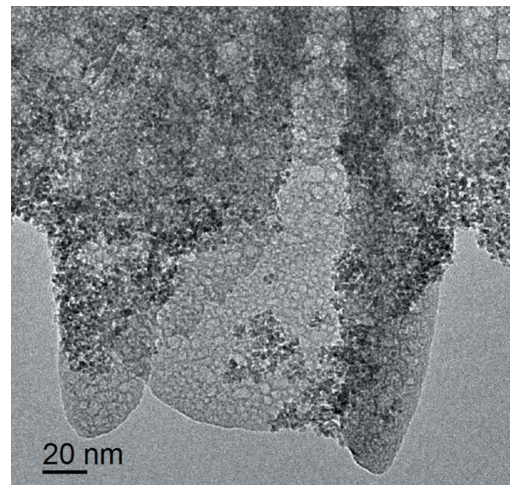

\section{SAXS study of the formation and structure of polynuclear thorium(IV) colloids and thorium dioxide nanoparticles}

\author{
Baihui Zhai, ${ }^{a}$ Qiang Tian, ${ }^{a}$ Na Li, ${ }^{\text {b }}$ Minhao Yan ${ }^{\mathrm{a} *}$ and Mark J. Henderson ${ }^{\mathrm{a} *}$ \\ ${ }^{a}$ State Key Laboratory of Environment-Friendly Energy Materials, Southwest University of Science and Technology, \\ Mianyang 621010, People's Republic of China, and ${ }^{\mathbf{b}}$ National Facility for Protein Science in Shanghai, Zhangjiang \\ Laboratory, Shanghai 201204, People's Republic of China. *Correspondence e-mail: yanminhao@swust.edu.cn, \\ mark_henderson@swust.edu.cn
}

Stable actinide colloids and nanoparticles are of interest because of their potential to affect the transportation of radionuclides in the near-field of a nuclear waste repository. At high concentrations, thorium(IV) can precipitate to form intrinsic colloids. In the present study, polynuclear thorium colloids and thorium dioxide crystallites, formed by the condensation of hydrolyzed $\mathrm{Th}^{4+}$ solutions ( $3 \mathrm{mM}$; initial $\mathrm{pH} 5.5)$ aged for up to 18 months, were studied using small-angle X-ray scattering. Scattering profiles were fitted using a unified Guinier/power-law model (Beaucage model) to extract the radii of gyration and Porod exponents. Analysis of the scattering profiles from a dispersion aged for 5 months indicated that both polymer coils and more compacted structures (radius of gyration $R_{\mathrm{g}} \simeq 10 \mathrm{~nm}$ ) were present, which translated in the Kratky plots as a plateau and a peak maximum, respectively. After 18 months, the SAXS data were consistent with the presence of agglomerates of $\mathrm{ThO}_{2}$ particles suspended in aqueous solution $(\mathrm{pH} 3.2 ;[\mathrm{Th}]=1.45 \mathrm{mM})$. The measured radius of gyration $\left(R_{\mathrm{g}}\right)$ of the agglomerates was $5.8 \mathrm{~nm}$, whereas the radius of the $\mathrm{ThO}_{2}$ particles was $2.5 \mathrm{~nm}$.

\section{Introduction}

Thorium, approximately three times more abundant than uranium, has received continuous attention from the nuclear fuel industry owing to its potential to minimize the production of plutonium in reactors based on thorium-based mixed-oxide fuels (Kabach et al., 2020; Drera et al., 2014). Current research in actinide (An) nanomaterials includes synthesis of oxide nanoparticles (Shi et al., 2017) and investigating the effects of size, shape and electronic structure on the physico-chemical properties of the materials. However, applications such as mining extraction, processing, tailings and residues provide a potential pathway for thorium to enter the soil-water environment (Aziman et al., 2021). Nanoparticles can exhibit much higher toxicities than their bulk forms because of their smaller sizes, larger surfaces areas and greater reactivities. For example, He et al. (2019) studied the toxicity of $\mathrm{ThO}_{2}$ nanoparticles on green algal cells. They showed that smaller $\mathrm{ThO}_{2}$ particles $(\simeq 50 \mathrm{~nm})$ had a higher affinity for attachment to the surface of green algal cells than larger particles.

Knowledge of the speciation and chemical behaviors of intrinsic thorium oxide nanoparticles/colloids has potential implications for the behavior of $\mathrm{Th}(\mathrm{IV})$ and, by analogy, An(IV) in the environment. Carrier- or pseudo-colloids formed by the adsorption of actinides onto natural aquatic colloids such as mineral fragments, humic substances and microorganisms might also increase the mobility of $\mathrm{Pu}(\mathrm{IV})$ in 
the far-field environment of a high-level nuclear waste repository (Romanchuk \& Kalmykov, 2020; Kersting, 2013; AbdelFattah et al., 2013). Colloids, in the form of amorphous or microcrystalline $\mathrm{An}(\mathrm{OH})_{4}(\mathrm{am})$ or $\mathrm{AnO}_{2} \cdot x \mathrm{H}_{2} \mathrm{O}(\mathrm{s})$, are solubility-limiting phases that play a key role in transporting the actinides to the near-field environment (Dumpala et al., 2021; Nishikawa et al., 2018). For thorium(IV), hydrolysis reactions produce a variety of oxides, hydroxides and complexes. For example, polynuclear species $\mathrm{Th}_{2}(\mathrm{OH})_{2}{ }^{6+}, \mathrm{Th}_{4}(\mathrm{OH})_{8}{ }^{8+}$ and $\mathrm{Th}_{4}(\mathrm{OH})_{12}{ }^{4+}$ (Aziman et al., 2021); $\mathrm{ThO}_{2}$ crystallites (Magini et al., 1976); hydrous thorium dioxide $\mathrm{ThO}_{2} \cdot n \mathrm{H}_{2} \mathrm{O}$ (Dzimitrowicz et al., 1985); amorpous $\mathrm{Th}(\mathrm{OH})_{4}$, aqueous $\mathrm{Th}(\mathrm{OH})_{4}$ and crystalline $\mathrm{ThO}_{2}$ (Neck \& Kim, 2001); microcrystalline $\mathrm{ThO}_{2} \cdot x \mathrm{H}_{2} \mathrm{O}(\mathrm{s})$, amorphous $\mathrm{ThO}_{n}(\mathrm{OH})_{4-2 n} \cdot x \mathrm{H}_{2} \mathrm{O}$ (Rothe et al., 2002); and $\left[\mathrm{Th}_{2}\left(\mu_{2}-\mathrm{OH}\right)_{2}\left(\mathrm{NO}_{3}\right)_{6}\left(\mathrm{H}_{2} \mathrm{O}\right)_{6}\right] \mathrm{H}_{2} \mathrm{O},\left[\mathrm{Th}_{2}\left(\mu_{2^{-}}\right.\right.$ $\left.\mathrm{OH})_{2}\left(\mathrm{NO}_{3}\right)_{4}\left(\mathrm{H}_{2} \mathrm{O}\right)_{8}\right]\left(\mathrm{NO}_{3}\right)_{2}$ and $\left[\mathrm{Th}_{2}\left(\mu_{2}-\mathrm{OH}\right)_{2} \mathrm{Cl}_{2}\left(\mathrm{H}_{2} \mathrm{O}\right)_{12}\right]$ $\mathrm{Cl}_{4} \cdot 2 \mathrm{H}_{2} \mathrm{O}$ (Wilson et al., 2007).

Thorium(IV) is an analog for studying the tetravalent state of the more radiologically and chemically toxic $\mathrm{Pu}(\mathrm{IV})$ because of their similar coordination chemistry (Li et al., 2020) and ionic radii which are $0.108 \mathrm{~nm}$ and $0.096 \mathrm{~nm}$ for thorium and plutonium, respectively. Despite minor differences in their properties, a tenfold coordination for $\mathrm{Th}^{4}$ and a slightly larger ionic radius, recent light scattering measurements of thorium polymers and colloids formed in the acidic solutions tend to highlight the similarities between the hydrolytic reactions of $\mathrm{Th}(\mathrm{IV})$ and $\mathrm{Pu}(\mathrm{IV})$ (Priyadarshini et al., 2016). Tetravalent actinide colloids relate to geological disposal of spent nuclear fuel (Zänker \& Hennig, 2014). Among the tetravalent actinide, thorium has attracted interest because of thoriumrelated contamination of the environment (Aziman et al., 2021). For example, thorium silicate (Hennig et al., 2013; Zänker et al., 2016) and thorite (Estevenon et al., 2020), which are stable in water at near-neutral $\mathrm{pH}$, have potential implications for colloidal transport in the environment. Speciation diagrams suggest that $\mathrm{Th}(\mathrm{OH})_{4}$ or $\mathrm{ThO}_{2} \cdot 2 \mathrm{H}_{2} \mathrm{O}$ are major colloids at neutral $\mathrm{pH}$, whereas $\mathrm{Th}_{x}(\mathrm{OH})_{\mathrm{y}}\left(\mathrm{CO}_{3}\right)_{2}{ }^{(4 x-y-2 x)}$ appears in the presence of carbonate, especially at higher $\mathrm{pH}$ values (Li et al., 2019). However, colloidal forms of thorium are reported to mobilize between $\mathrm{pH} 2$ and $\mathrm{pH} 10$ ( $\mathrm{Li}$ et al., 2019), the $\mathrm{pH}$ range of natural waters (Silva \& Nitsche, 1995).

In this work, small-angle X-ray scattering (SAXS) from polynuclear thorium(IV) colloids and thorium oxide nanoparticles are discussed. SAXS has previously been used to investigate the hydrolysis behavior of $\mathrm{Th}^{4+}$ solutions (Magini et al., 1976). These authors showed that polynuclear thorium complexes form at room temperature, whereas agglomerates of $\mathrm{ThO}_{2}$ crystallites are induced by a nonhydrothermal treatment. Here, we applied the model developed by Beaucage (Beaucage \& Schaefer, 1994; Beaucage, 1995, 1996) to SAXS data obtained from thorium polymer/nanoparticle dispersions. Our aim is to highlight the various stable colloidal forms (hydroxide-bridged complexes, oxygen-bridged polymers and oxide nanoparticles) dispersed in aqueous solutions aged for up to 18 months. This knowledge will be used to understand the interaction between Th(IV) colloids and clay buffer material within a proposed deep geological repository.

\section{Experimental}

\subsection{Materials}

Thorium nitrate tetrahydrate $\left(\mathrm{Th}\left(\mathrm{NO}_{3}\right)_{4} \cdot 4 \mathrm{H}_{2} \mathrm{O}\right)$ was purchased from Chengdu Beyond Chemical Co. Ltd. Sodium hydroxide $(\mathrm{NaOH}, \geq 96.0 \%$, Chengdu Jinshan Chemical Reagent Co. Ltd) was used as received.

\subsection{Synthesis of thorium colloids and nanoparticles}

Thorium colloids were synthesized under a nitrogen atmosphere to avoid the possible reaction of thorium polymers with carbonates formed in the presence of $\mathrm{CO}_{2}$. A stock solution of $\mathrm{Th}\left(\mathrm{NO}_{3}\right)_{4} \cdot 4 \mathrm{H}_{2} \mathrm{O}\left(30 \mathrm{ml} ; 3 \mathrm{mmol} \mathrm{l}{ }^{-1} ; \mathrm{pH} 2.5\right)$, denoted sample $\mathrm{T}_{0}$, was adjusted to pH $5.5\left(\mathrm{~T}_{1}\right), 6.0\left(\mathrm{~T}_{2}\right), 6.5\left(\mathrm{~T}_{3}\right), 7.5\left(\mathrm{~T}_{4}\right)$ and $8.0\left(\mathrm{~T}_{5}\right)$ using $\mathrm{NaOH}$ solution $\left(0.1 \mathrm{~mol} \mathrm{l}^{-1}\right)$. Two sets of mixtures were made. An aliquot of the clear colorless dispersion was removed above the precipitate when synchrotron SAXS beam time became available, i.e. after 26 days and 166 days.

\subsection{Characterization methods}

The synchrotron SAXS measurements were performed at the BL19U2 beamline at the Shanghai Synchrotron Radiation Facility (China). A flow cell made of a quartz capillary with a diameter of $1.5 \mathrm{~mm}$ and a wall thickness of $10 \mu \mathrm{m}$ was used to withdraw an aliquot of thorium dispersions. The SAXS patterns were recorded using a Pilatus $1 \mathrm{M}$ detector (DECTRIS) with a pixel size of $172 \mu \mathrm{m}$. Intensity profiles were denoted $I(Q)$ and plotted as the magnitude of the scattering vector magnitude $Q=(4 \pi \sin \theta) / \lambda$, where $\lambda$ is the wavelength of the incident $\mathrm{X}$-rays and $\theta$ is half the scattering angle. The wavelength was tuned to $0.09184 \mathrm{~nm}$ and the sample-to-detector distance was $5660 \mathrm{~mm}$, resulting in the $Q$ range $0.07-3.6 \mathrm{~nm}^{-1}$.

The SAXS measurements were also performed with a SAXSpace instrument (Anton Paar, Austria; $40 \mathrm{kV}$ and $50 \mathrm{~mA}$ ) when conformational changes were no longer observed. The wavelength of the X-ray radiation was $\lambda=$ $0.1542 \mathrm{~nm}$. The SAXS patterns were recorded using a Mythen2 R 1K (Dectris, Switzerland) detector, positioned $317 \mathrm{~mm}$ from the samples. The recorded patterns showed the $Q$ range $0.05 \mathrm{~nm}^{-1}-7.8 \mathrm{~nm}^{-1}$, which has an extended $Q$ range towards wide angles compared with the setup of the BL19U2 beamline and, as a result, the SAXSpace instrument has an advantage for measuring small particles. The data were fitted by the least-squares method using the SASfit software (version 0.94.6; Breßler et al., 2015) according to the unified Guinier/ power-law (Beaucage \& Schaefer, 1994; Beaucage, 1995, 1996),

$$
\begin{aligned}
& I(Q) \simeq \\
& \quad G \exp \left(-\frac{Q^{2} R_{\mathrm{g}}^{2}}{3}\right)+\frac{B}{Q^{P}} \exp \left(-\frac{Q^{2} R_{\mathrm{sub}}^{2}}{3}\right)\left[\operatorname{erf}\left(\frac{Q k R_{\mathrm{g}}}{\sqrt{6}}\right)\right]^{3 P} \\
& +G_{\mathrm{s}} \exp \left(-\frac{Q^{2} R_{\mathrm{s}}^{2}}{3}\right)+\frac{B_{\mathrm{s}}}{Q^{P_{\mathrm{s}}}}\left[\operatorname{erf}\left(\frac{Q k_{\mathrm{s}} R_{\mathrm{s}}}{\sqrt{6}}\right)\right]^{3 P_{\mathrm{s}}}
\end{aligned}
$$


where $R_{\mathrm{g}}, R_{\text {sub }}$ and $R_{\mathrm{s}}$ are the radius of gyration of large, medium and small structures in the studied system, respectively; $P$ and $P_{\mathrm{s}}$ are the scaling exponents of the power-law scattering from the large and small structures; and $G$ and $B$ are the Guinier and the Porod law prefactors.

Transmission electron microscopy (TEM) was performed using a Zeiss Libra200FE microscope by droplet evaporation of the Th dispersion on a Cu TEM grid. Solution $\mathrm{pH}$ measurements were recorded with an Accumet XL200 pH (Fischer Scientific) meter equipped with an E-201F pH probe (Shanghai REX Sensor technology Company). Thorium levels were determined by Inductively Coupled Plasma Optical Emission Spectrometry (ICP-OES) analyses using an ICPOES 730 instrument (Agilent).

\section{Results}

The SAXS profiles of samples $\mathrm{T}_{0}-\mathrm{T}_{5}$ prepared between $\mathrm{pH} 2.5$ and $\mathrm{pH} 8.0$ and aged for 166 days are shown in Fig. 1. Scattering intensities were found to decrease with an increase in the initial $\mathrm{pH}$. At the highest $\mathrm{pH}$ limit the scattering profile was found to be similar to that of the thorium stock solution, $\mathrm{T}_{0}$, from which all the dispersions were made. Note that with the exception of sample $\mathrm{T}_{0}$, the $\mathrm{pH}$ values of all solutions decreased from their initial values to $\mathrm{pH} 3.5\left(\mathrm{~T}_{1}\right), \mathrm{pH} 3.4\left(\mathrm{~T}_{2}\right)$, pH $3.7\left(\mathrm{~T}_{3}\right), \mathrm{pH} 3.7\left(\mathrm{~T}_{4}\right)$ and $\mathrm{pH} 4.3\left(\mathrm{~T}_{5}\right)$ after 166 days. Also, only samples prepared under the most acidic conditions at $\mathrm{pH} 5.5$ showed scattering after they were aged for 26 days (not reported).

These results suggest that both the solution acidity and aging time direct the amount of thorium colloids in solution above the precipitate. Based on these preliminary results, the scattering profiles from sample $\mathrm{T}_{1}$ aged for 26 days and for 166 days were selected for further analysis. The synchrotronradiation SAXS profiles for the $\mathrm{Th}^{4+}$ stock solution and the sample $T_{1}$ aged for 26 and 166 days are shown in Figs. 2(a)-

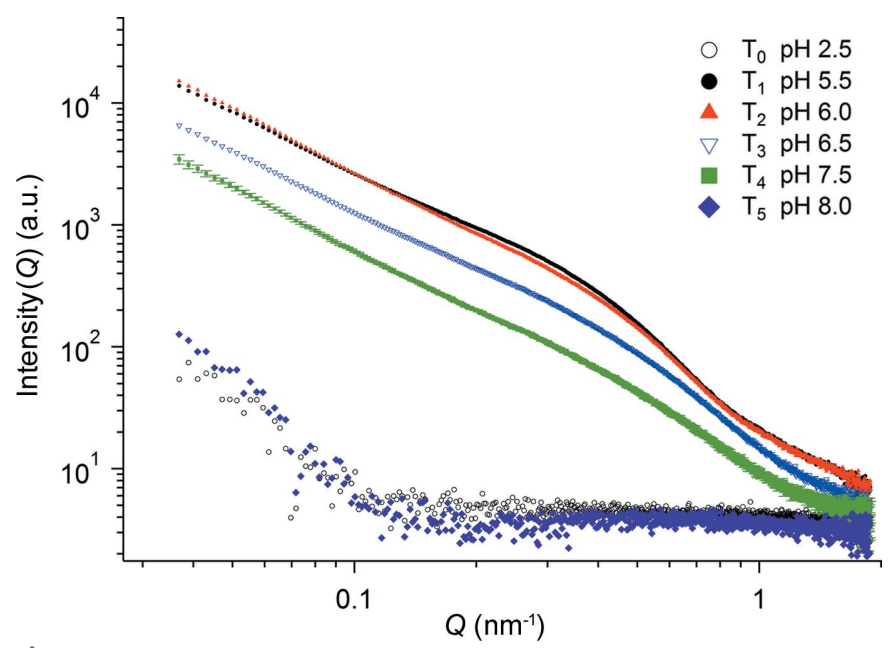

Figure 1

Synchrotron radiation SAXS profiles obtained from aqueous thorium solutions prepared at initial $\mathrm{pH}$ values $2.5-8.0$ and aged for 166 days: $\mathrm{T}_{0}$ (open circles), $T_{1}$ (filled black circles), $T_{2}$ (filled red triangles), $T_{3}$ (open blue triangles), $\mathrm{T}_{4}$ (filled green squares) and $\mathrm{T}_{5}$ (filled purple diamonds).

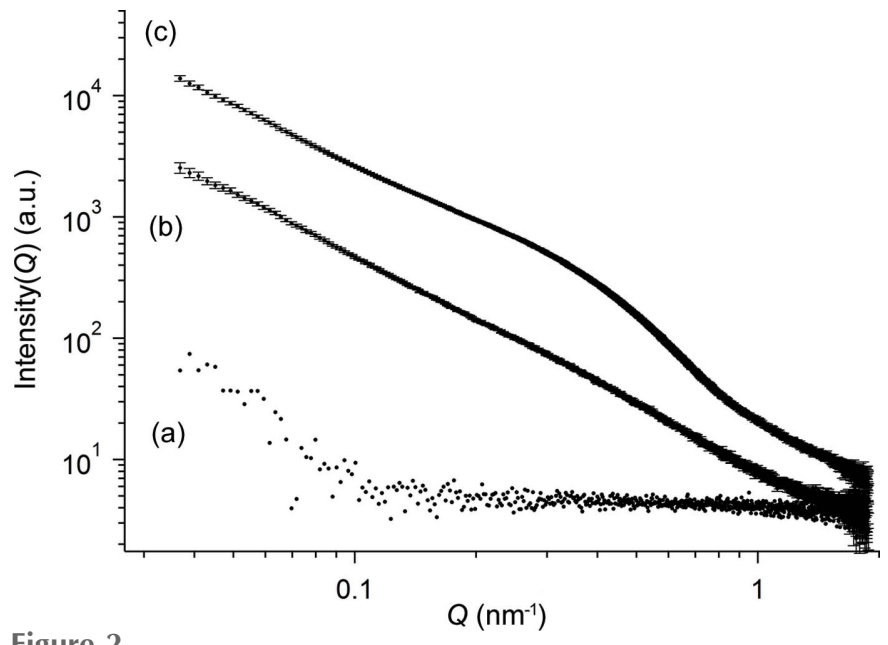

Figure 2

Synchrotron radiation SAXS profiles obtained from $(a)$ sample $\mathrm{T}_{0},(b)$ sample $\mathrm{T}_{1}$ at 26 days ( $\mathrm{pH} 4.1$ ) and (c) sample $\mathrm{T}_{1}$ at 166 days ( $\mathrm{pH} 3.5$ ).

2(c). The SAXS profile of the dispersion after 26 days [Fig. 2(b)] showed strong scattering and a power scattering $\left(I \propto Q^{-\alpha}\right.$ with exponent $\left.\alpha=1.7\right)$ in the $Q$ range from $0.04 \mathrm{~nm}^{-1}$ to $0.2 \mathrm{~nm}^{-1}$, which is characteristic of scattering from a self-avoiding random walk chain (Schurtenberger, 2002). The features of this scattering profile and a concomitant fall in the solution $\mathrm{pH}$ from 5.5 to 4.1 were interpreted in terms of the presence of hydroxyl-bridged structures, namely, $\mathrm{Th}_{x}(\mathrm{OH})_{y}{ }^{(4 x-y)}$ polymers (Wickleder et al., 2006). The scattering profile obtained from the dispersion aged for 166 days [Fig. 2(c)] shows an additional feature at $Q \simeq 0.35 \mathrm{~nm}^{-1}$, an indication that the thorium polymers coexist with smaller objects in the dispersion.

The scattering profile shown in Fig. 2(c) was analyzed by the unified Guinier/power-law (Fig. 3). The SAXS curve displays power slopes at low- $Q\left(0.03-0.24 \mathrm{~nm}^{-1}\right)$, mid- $Q$ $\left(0.2-0.8 \mathrm{~nm}^{-1}\right)$ and high- $Q\left(0.5-1.9 \mathrm{~nm}^{-1}\right)$ ranges, i.e. three structural levels are described. At low- $Q$ the power-law exponent (1.7) was found to be similar to that obtained from the profile after 26 days. Note that because the size of the polymer network was beyond the maximum size limit of this instrument $(\pi / 0.03 \simeq 100 \mathrm{~nm}), R_{\mathrm{g}}$ was arbitrarily set to a higher value, in this case $200 \mathrm{~nm}$. At mid- $Q$ the fit yielded a power-law exponent of 2.3, which relates to a branched fractal network more compacted than that displayed by the polymers. The radii of these new objects were estimated to be $\sim 10 \mathrm{~nm}$. At high- $Q$, a power-law regime with an exponent of 4 is observed, and $R_{\mathrm{g}} \simeq 1.8 \mathrm{~nm}$ corresponds to the gyration radius of smallest particles found in this sample. The results of the analysis are summarized in Table 1.

Transmission electron micrographs obtained from samples $\mathrm{T}_{1}$ and $\mathrm{T}_{3}$ after aging for 6 months (Fig. 4) show two features. One is the high-density particles with radii $<2 \mathrm{~nm}$, in agreement with the Beaucage modeling of the high- $Q$ SAXS data. The other is the low-density network, which can be attributed to dried $\mathrm{Th}(\mathrm{IV})$ polymer solution species, as indicated by the power-law exponents of 1.7 and 2.3 derived from SAXS data (Table 1). 

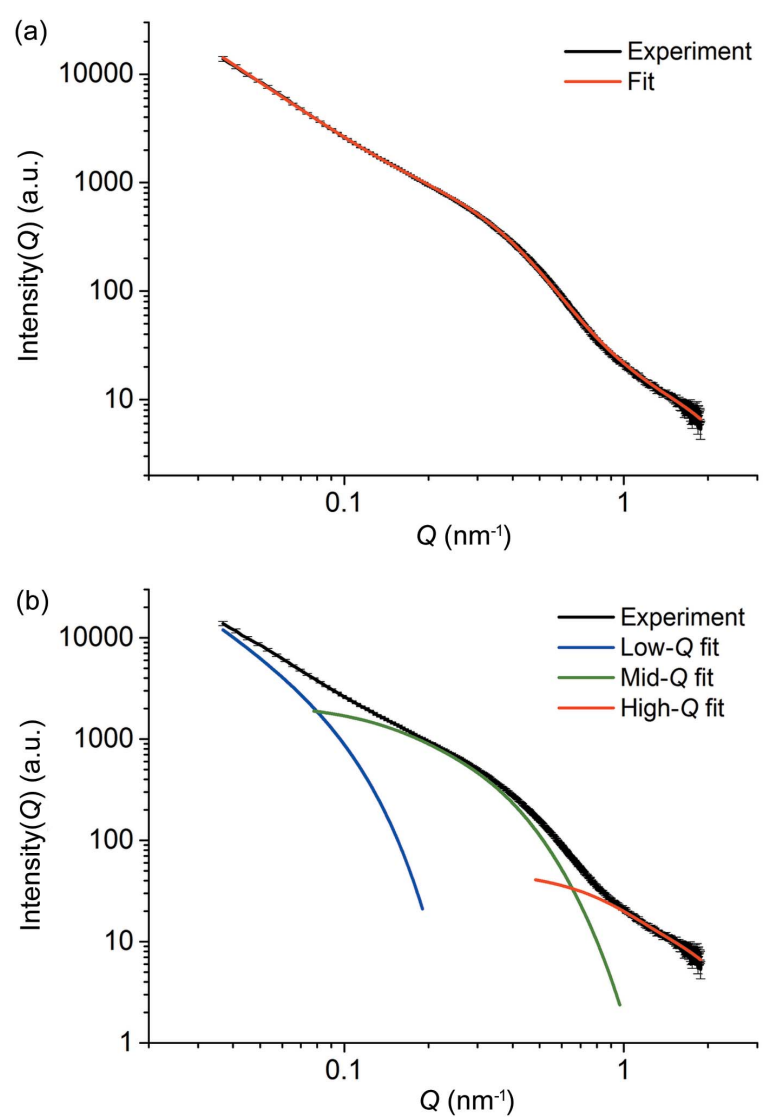

Figure 3

(a) Experimental data (closed black circles) for SAXS from sample $\mathrm{T}_{1}$ (pH 3.5) aged for 166 days. The red line is the approximation by the unified Guinier/power-law equation. (b) Colored lines are the fitting functions obtained using the unified Guinier/power-law equation for the low- $Q$ (blue line), mid- $Q$ (green line) and high- $Q$ (red line) ranges.

To highlight the polymer and dense particle structures, the SAXS data of Fig. 2 were expressed as Kratky plots $\left(I Q^{2}-Q\right)$ (Fig. 5), which are useful to highlight changes in the compactness of polymers (Fairclough et al., 1999) and proteins (Kikhney \& Svergun, 2015) in solution. A bell-shaped curve is obtained when the scattered intensity decays as $Q^{-4}$, i.e. scattering from solid objects. A plateau at high- $Q$ values is obtained when the scattering intensity decays as $Q^{-2}$, i.e. scattering from extended structures such as a Gaussian chain. For the thorium dispersions used here, the transition from polymers to oxide particles was characterized by a plateau [Fig. 5(b)] and a bell-shaped curve [Fig. 5(c)] indicating a coil and a compacted structure, respectively.

Prolonged aging of the dispersion for 18 months resulted in a gradual decrease of solution $\mathrm{pH}$ from 3.5 to 3.2. SAXS measurements of this dispersion were recorded (Fig. 6). The $I-Q$ curve shows a plateau at $Q<0.2 \mathrm{~nm}^{-1}$, a strong decay at $0.2 \mathrm{~nm}^{-1}<Q<0.8 \mathrm{~nm}^{-1}$, a knee at $0.8 \mathrm{~nm}^{-1}<Q<2 \mathrm{~nm}^{-1}$ and a background at $Q>4 \mathrm{~nm}^{-1}$. This result implies that two levels of particle structure were present in the dispersion.

The size and shape of the scattering objects were extracted from the measured data using a unified exponential-power-law model using two structural levels. The results of the Beaucage
Table 1

Parameters obtained from the fitted SAXS profile obtained from an aqueous thorium solution aged for 166 days (sample $\mathrm{T}_{1}$; $\mathrm{pH} 3.5$ ).

\begin{tabular}{|c|c|c|c|c|c|}
\hline \multicolumn{2}{|l|}{ Low- $Q$} & \multicolumn{2}{|l|}{ Mid- $Q$} & \multicolumn{2}{|l|}{ High- $Q$} \\
\hline$R_{\mathrm{g}}(\mathrm{nm})$ & $P$ & $R_{\mathrm{s}}(\mathrm{nm})$ & $P$ & $R_{\mathrm{s}}(\mathrm{nm})$ & $P_{\mathrm{s}}$ \\
\hline 200 & $1.7 \pm 0.1$ & $9.5 \pm 0.2$ & $2.3 \pm 0.1$ & $1.77 \pm 0.07$ & 4.0 \\
\hline
\end{tabular}

model analysis showed that two particle sizes of radii $\left(R_{\mathrm{g}}\right)$ $5.8 \mathrm{~nm}$ and $2.5 \mathrm{~nm}$ were present in this dispersion (Table 2).

A TEM micrograph of the particles obtained from the aged dispersion is shown in Fig. 7(a). The agglomerations are composed of monodisperse primary particles of approximately $5 \mathrm{~nm}$ diameter [Fig. 7(b)] in agreement with the SAXS Beaucage modeling.

The size was also similar to the mean diameter found for $\mathrm{ThO}_{2}$ nanoparticles synthesized by a non-aqueous route (Hudry et al., 2013). Furthermore, the lattice fringes shown in

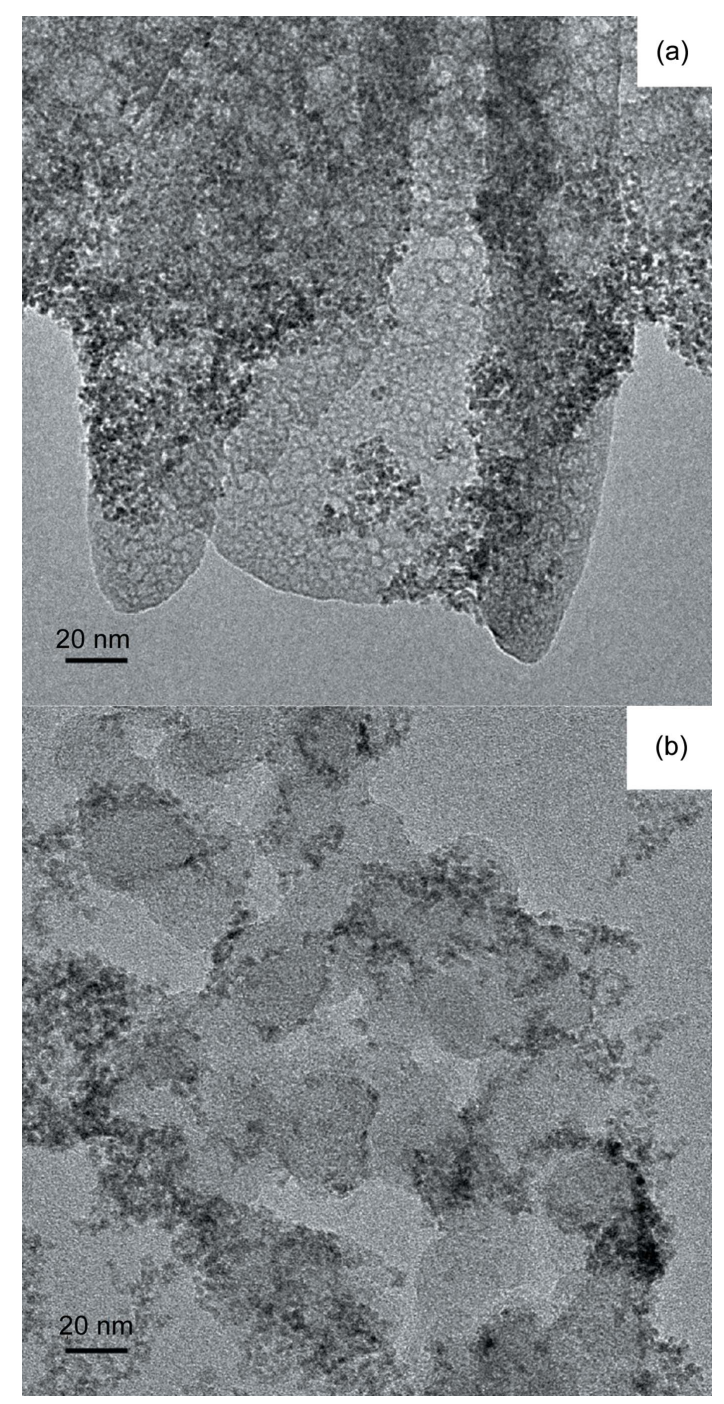

Figure 4

Transmission electron micrographs obtained from aqueous thorium dispersions aged for approximately 6 months: $(a) \mathrm{T}_{1}$ and $(b) \mathrm{T}_{3}$. 


\section{actinide physics and chemistry}

Table 2

Parameters extracted from the fitted SAXS profile obtained from an aqueous thorium solution aged for 18 months (sample $\mathrm{T}_{1} ; \mathrm{pH} 3.2$ ).

\begin{tabular}{lll}
\hline$R_{\mathrm{g}}(\mathrm{nm})$ & $P$ & $R_{\mathrm{s}}(\mathrm{nm})$ \\
\hline $5.8 \pm 0.5$ & 4 & $2.5 \pm 0.5$ \\
\hline
\end{tabular}

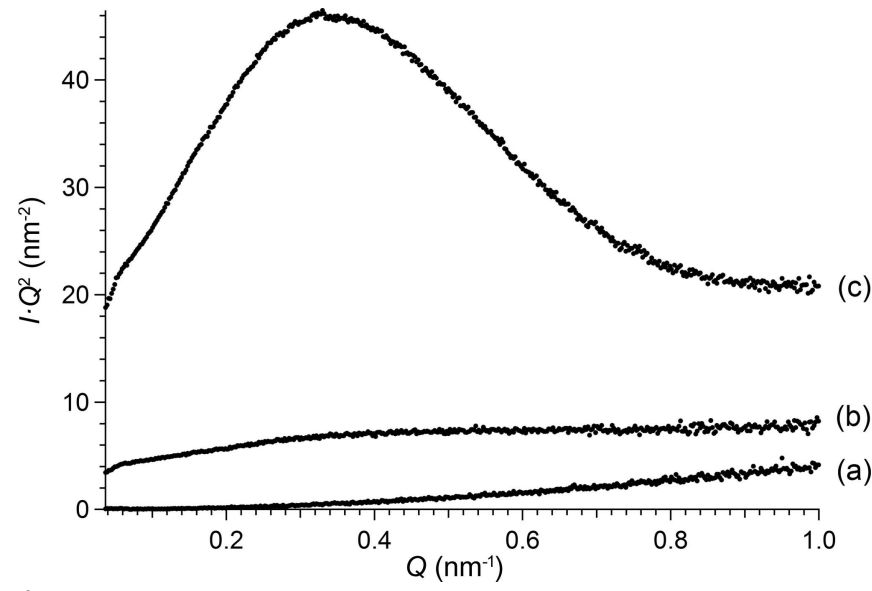

Figure 5

Kratky plots $\left(I Q^{2}-Q\right)$ obtained from SAXS measurements: $(a)$ sample $\mathrm{T}_{0}$, (b) sample $\mathrm{T}_{1}$ at 26 days ( $\mathrm{pH} 4.1$ ) and (c) sample $\mathrm{T}_{1}$ at 166 days ( $\mathrm{pH} 3.5$ ). Data from Fig. 2.

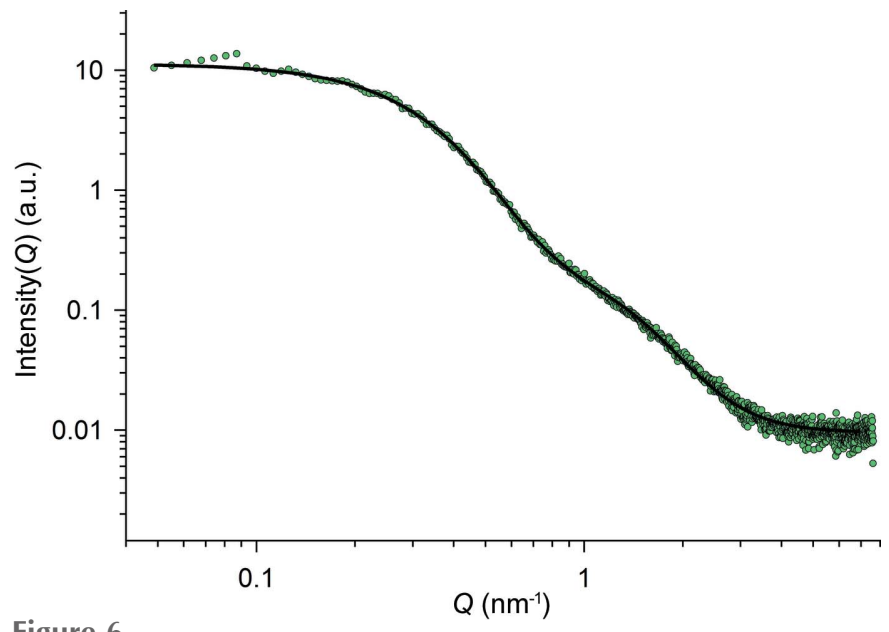

Figure 6

SAXS profile (Anton Paar SAXSpace) obtained from a thorium dispersion aged for 18 months, $\mathrm{pH} 3.2$ (green circles), [Th] $=1.45 \mathrm{mM}$. The unified exponential-power-law fit to the data is shown as a black line.

Fig. $7(b)$ indicate the microcrystalline structure of the primary particles [Fig. $7(b)]$. This lattice space $(0.34 \pm 0.02 \mathrm{~nm})$ is consistent with the value obtained from a precipitate with the composition $\mathrm{ThO}_{2} \cdot 2.5 \mathrm{H}_{2} \mathrm{O}(\mathrm{s})(0.34 \mathrm{~nm})$ (Dzimitrowicz et al., 1985) despite the different method of sample preparation, namely, fast precipitation from concentrated thorium solution at near-neutral conditions. More recently it was shown that freshly precipitated thorium prepared by titration using base consists of a hydrated oxyhydroxide, $\mathrm{ThO}_{n}(\mathrm{OH})_{4-2 n}$. $x \mathrm{H}_{2} \mathrm{O}(\mathrm{am})$ (Rothe et al., 2002). In the present study, SAXS and TEM results led to the conclusion that agglomerates of microcrystalline $\mathrm{ThO}_{2}$ particles $(5 \mathrm{~nm})$ were formed in solution after 18 months. The results are in agreement with the

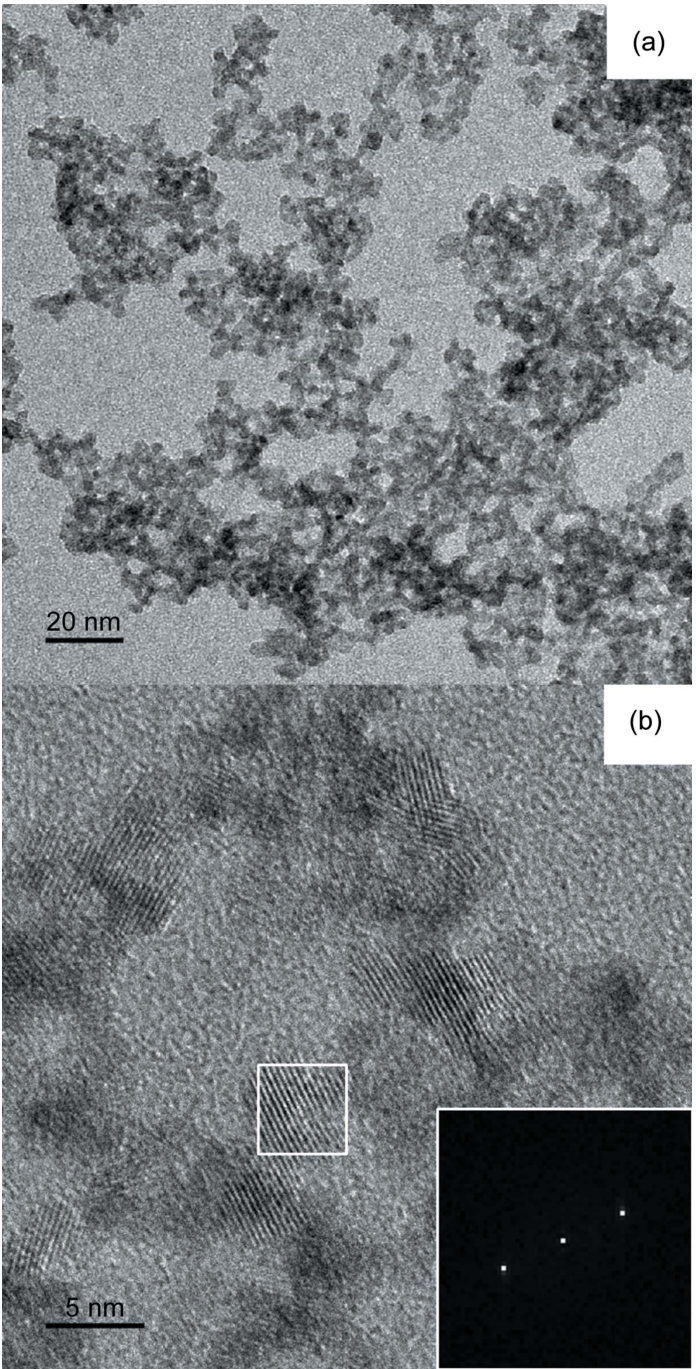

Figure 7

Transmission electron micrograph results from $\mathrm{ThO}_{2}$ particles obtained from an aqueous dispersion prepared by hydrolysis of $\mathrm{Th}\left(\mathrm{NO}_{3}\right)_{4} \cdot 4 \mathrm{H}_{2} \mathrm{O}$ solution and aged for 18 months: (a) low-resolution image, $(b)$ highresolution image showing the lattice fringes of a crystallite and its corresponding FFT (inset).

formation of agglomerates of thorium dioxide crystallites (3-4 nm) induced by thermal treatment of an aqueous solution of hydrolyzed thorium species (Magini et al., 1976).

\section{Discussion}

Our interest is the formation of thorium polymers and particles in solution above the precipitate after the initial hydrolysis step, e.g. polynuclear hydroxide complexes $\mathrm{Th}_{x}(\mathrm{OH})_{y}{ }^{4 x-y}$ and thorium(IV) colloids $\left[\mathrm{Th}(\mathrm{OH})_{4}(\mathrm{am})\right]$ (Rothe et al., 2002). Our SAXS study builds on the work by Magini et al. (1976) who studied the speciation of hydrolyzed thorium solutions at room temperature and at $80-90^{\circ} \mathrm{C}$ by small-angle and wide-angle X-ray scattering. The solution hydrolyzed at room temperature contained the suggested complex $\left[\mathrm{Th}_{6} \mathrm{O}(\mathrm{OH})_{6}\left(\mathrm{H}_{2} \mathrm{O}\right)_{n}\right]^{16+}$, whereas the heat-treated solutions contained agglomerates of $\mathrm{ThO}_{2}$ particles (Table 3). 
Table 3

Sizes of intrinsic thorium colloids suspended in aqueous solution.

\begin{tabular}{|c|c|c|c|c|}
\hline Colloid designation & $\mathrm{pH}$ & Size $(\mathrm{nm})$ & Technique & Reference \\
\hline $\mathrm{ThO}_{2}$ crystallites & - & 4 and 17 & SAXS & Magini et al. (1976) \\
\hline $\begin{array}{l}\text { Microcrystalline } \\
\mathrm{ThO}_{2}\end{array}$ & $1.5-2.6$ & $16-23$ & LIBD $\dagger$ & Bundschuh et al. (2000) \\
\hline $\mathrm{Th}(\mathrm{OH})_{4}(\mathrm{am})$ & 3.62 & $>5$ & LIBD & Rothe et al. (2002) \\
\hline $\begin{array}{l}\text { Cationic hydrous } \\
\mathrm{ThO}_{2}\end{array}$ & $2.0-2.5$ & $1-1.7$ & TEM & Lünsdorf et al. (2006) \\
\hline Thorium colloids & $2.9-3.3$ & $13.4-19.6$ & LIBD & Dumpala et al. (2021) \\
\hline $\begin{array}{l}\text { Microcrystalline } \\
\mathrm{ThO}_{2} \ddagger\end{array}$ & 3.2 & 5 and 12 & SAXS & This study \\
\hline
\end{tabular}

$\dagger$ Laser-induced breakdown detection. $\ddagger$ Dispersion aged for 18 months.

In this study we have applied the unified Guinier/power-law model to SAXS data obtained from thorium polymer/nanoparticle dispersions above the precipitate after aging the sample for 5 months and 18 months at room temperature. The model was particularly useful when applied to the SAXS profile obtained from a dispersion aged for 5 months where the Guinier region, which defined the radius of gyration $\left(R_{\mathrm{g}}=\right.$ $10 \mathrm{~nm}$ ) of the colloids, was obscured by low- $Q$ scattering from the thorium polymers. Based on the power-law exponent of 2.3 extracted from the Beaucage modeling of the mid- $Q$ range SAXS data, which indicates a loose-packed structure, these particles are most likely amorphous hydroxide $\mathrm{Th}(\mathrm{OH})_{4}(\mathrm{am})$ or hydrous oxides $\mathrm{ThO}_{2} \cdot x \mathrm{H}_{2} \mathrm{O}(\mathrm{am})$. Furthermore, the differences in these thorium colloid structures were translated in the Kratky plots as either a plateau, a characteristic feature of an ideal Gaussian chain, or a peak maximum suggesting scattering from a more condensed phase. After 18 months, the sizes of two discrete populations of primary $\left(R_{\mathrm{g}}=2.5 \mathrm{~nm}\right)$ and secondary particles $\left(R_{\mathrm{g}}=5.8 \mathrm{~nm}\right)$ could be quantified by application of the Beaucage model to the scattering curve. In short, the SAXS technique was able to discern polymer from particles, and in the fully aged dispersion discern two discrete populations of primary and secondary particles.

The SAXS profile (Fig. 6) shows a plateau at $Q<0.2 \mathrm{~nm}^{-1}$, an indication that $\mathrm{Th}_{x}(\mathrm{OH})_{y}{ }^{(4 x-y)}$ polymers were not present in solution after prolonged aging at room temperature. The $\mathrm{pH}$ of this dispersion was 3.2. This result is consistent with the formation of the oxo-species by the loss of a proton from each hydroxyl group rather than by the irreversible elimination of water (Johnson \& Toth, 1978; Dumpala et al., 2021). Based on the results from this study, the hydrolytic behavior is summarized in Fig. 8.

These $\mathrm{ThO}_{2}$ nanoparticles are designated as microcrystalline $\mathrm{ThO}_{2}$, i.e. most likely they have a hydrated surface and correspond to the generalized composition $\mathrm{ThO}_{2} \cdot x \mathrm{H}_{2} \mathrm{O}(\mathrm{s})$ (Rothe et al., 2002). In this report, the Beaucage model described both Guinier and Porod regions of a scattering curve, and was used to obtain the radii of gyration and power scattering exponents from different structural levels. More recently it was shown that unwanted artifacts are introduced when the Guinier and Porod prefactors are allowed to vary independently (Hammouda, 2010). However, the scattering curves shown in Figs. 1 and 2(c) were sufficiently featured, e.g. by a prominent knee at mid- $Q$ values to warrant the use of the Beaucage model.

\section{Conclusions}

Thorium colloids dispersed in aqueous solution and aged for up to 18 months were studied by SAXS. The results of the Beaucage modeling demonstrated that the dispersion aged for 5 months contained polynuclear Th(IV) solution species including colloids $\sim 20 \mathrm{~nm}$ in diameter, and thorium dioxide particles $(3-4 \mathrm{~nm})$. These SAXS results suggest that the polymers have a low-density network. However, the dispersion aged for 18 months contained only microcrystalline $\mathrm{ThO}_{2}$ particles $(5 \mathrm{~nm})$ agglomerated to form larger particles $(\sim 12 \mathrm{~nm})$. Further work is necessary to examine the generation and stability of thorium nanoparticles under near-neutral $\mathrm{pH}$ conditions.

\section{Acknowledgements}

Dr Kun Xiong is gratefully acknowledged for assistance with the TEM analysis. The authors declare that they have no known competing interests.

\section{Funding information}

The following funding is acknowledged: National Natural Science Foundation of China (grant No. U1932117), Sichuan 1000 Talents Scholar Program (grant No. 846), Sichuan Science and Technology Program (grant No. 2020YFH0119), Research Funding of Southwest University of Science and Technology (grant No. 15zxt101).

\section{References}

Abdel-Fattah, A. I., Zhou, D., Boukhalfa, H., Tarimala, S., Ware, S. D. \& Keller, A. A. (2013). Environ. Sci. Technol. 47, 5626-5634.

Aziman, E. S., Mohd Salehuddin, A. H. J. \& Ismail, A. F. (2021). Sep. Purif. Rev. 50, 177-202.

Beaucage, G. (1995). J. Appl. Cryst. 28, 717-728.

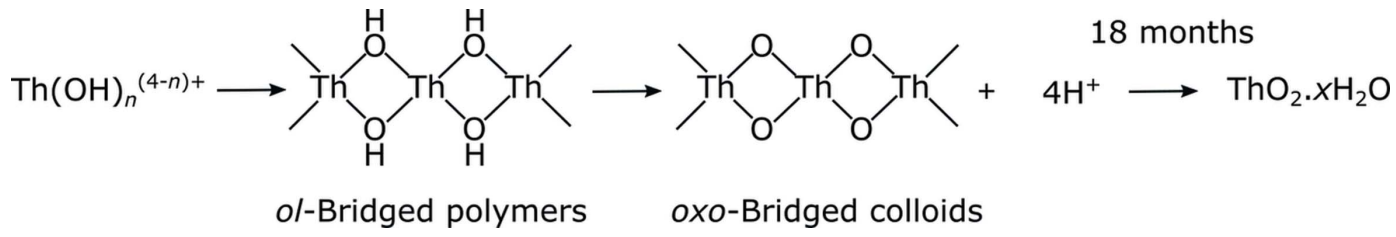

Figure 8

Summary of the hydrolytic behavior of $\mathrm{Th}^{4+}$ solution $(3 \mathrm{mM})$ from an initial $\mathrm{pH} 5.5$, and aged for 18 months at room temperature (pH 3.2 ; $[\mathrm{Th}]=1.45 \mathrm{~m} M)$. 
Beaucage, G. (1996). J. Appl. Cryst. 29, 134-146.

Beaucage, G. \& Schaefer, D. W. (1994). J. Non-Cryst. Solids, 172-174, 797-805.

Breßler, I., Kohlbrecher, J. \& Thünemann, A. F. (2015). J. Appl. Cryst. 48, 1587-1598.

Bundschuh, T., Knopp, R., Müller, R., Kim, J. I., Neck, V. \& Fanghänel, T. (2000). Radiochim. Acta, 88, 625-629.

Drera, S. S., Insulander Björk, K. \& Kelly, J. F. (2014). Prog. Nucl. Energy, 72, 5-10.

Dumpala, R. M. R., Sahu, M., Nagar, B. K., Raut, V. V., Raje, N. H., Rawat, N., Subbiah, J., Saxena, M. K. \& Tomar, B. S. (2021). Chemosphere, 269, 129327.

Dzimitrowicz, D. J., Wiseman, P. J. \& Cherns, D. (1985). J. Colloid Interface Sci. 103, 170-177.

Estevenon, P., Causse, J., Szenknect, S., Welcomme, E., Mesbah, A., Moisy, P., Poinssot, C. \& Dacheux, N. (2020). Dalton Trans. 49, 11512-11521.

Fairclough, J. P. A., Hamley, I. W. \& Terrill, N. J. (1999). Radiat. Phys. Chem. 56, 159-173.

Hammouda, B. (2010). J. Appl. Cryst. 43, 716-719.

He, X., Xie, C., Ma, Y., Wang, L., He, X., Shi, W., Liu, X., Liu, Y. \& Zhang, Z. (2019). Aquat. Toxicol. 209, 113-120.

Hennig, C., Weiss, S., Banerjee, D., Brendler, E., Honkimäki, V., Cuello, G., Ikeda-Ohno, A., Scheinost, A. C. \& Zänker, H. (2013). Geochim. Cosmochim. Acta, 103, 197-212.

Hudry, D., Apostolidis, C., Walter, O., Gouder, T., Courtois, E., Kübel, C. \& Meyer, D. (2013). Chem. Eur. J. 19, 5297-5305.

Johnson, G. L. \& Toth, L. M. (1978). Plutonium(IV) and Thorium(IV) Hydrous Polymer Chemistry. [Conversion of Hydrolye-Bridged Polymer Links to Oxygen-Bridged Linkages], Springfield: Oak Ridge National Laboratory.

Kabach, O., Chetaine, A., Benchrif, A. \& Amsil, H. (2020). Ann. Nucl. Energy, 140, 107075.

Kersting, A. B. (2013). Inorg. Chem. 52, 3533-3546.
Kikhney, A. G. \& Svergun, D. I. (2015). FEBS Lett. 589, 2570-2577.

Li, Z., Hadioui, M. \& Wilkinson, K. J. (2019). Environ. Pollut. 247, 206-215.

Li, Z.-J., Guo, S., Lu, H., Xu, Y., Yue, Z., Weng, L., Guo, X., Lin, J. \& Wang, J.-Q. (2020). Inorg. Chem. Front. 7, 260-269.

Lünsdorf, H., Kristen, I. \& Barth, E. (2006). BMC Microbiol. 6, 59.

Magini, M., Cabrini, A., Scibona, G., Johansson, G. \& Sandström, M. (1976). Acta Chem. Scand. 30a, 437-447.

Neck, V. \& Kim, J. I. (2001). Radiochim. Acta, 89, 1-16.

Nishikawa, S., Kobayashi, T., Sasaki, T. \& Takagi, I. (2018). Radiochim. Acta, 106, 655-667.

Priyadarshini, N., Sampath, M., Kumar, S. \& Kamachi Mudali, U. (2016). J. Radioanal. Nucl. Chem. 307, 25-30.

Romanchuk, A. Y. \& Kalmykov, S. N. (2020). Behavior of Radionuclides in the Environment I: Function of Particles in Aquatic System, edited by K. Kato, A. Konoplev \& S. N. Kalmykov, pp. 151-176. Singapore: Springer Singapore.

Rothe, J., Denecke, M. A., Neck, V., Müller, R. \& Kim, J. I. (2002). Inorg. Chem. 41, 249-258.

Schurtenberger, P. (2002). Neutrons, X-rays and Light: Scattering Methods Applied to Soft Condensed Matter, edited by P. Lindner \& T. Zemb, pp. 259-298. Amsterdam: Elsevier.

Shi, W. Q., Mei, L. \& Chai, Z. F. (2017). Modern Inorganic Synthetic Chemistry, 2nd ed., edited by R. Xu \& Y. Xu, pp. 355-387. Amsterdam: Elsevier.

Silva, R. J. \& Nitsche, H. (1995). Radiochim. Acta, 70-71, 377-396.

Wickleder, M. S., Fourest, B. \& Dorhout, P. K. (2006). The Chemistry of the Actinide and Transactinide Elements, Vol. 1, edited by L. R. Morss, N. M. Edelstein, J. Fuger \& J. Katz, Dordrecht: Springer.

Wilson, R. E., Skanthakumar, S., Sigmon, G., Burns, P. C. \& Soderholm, L. (2007). Inorg. Chem. 46, 2368-2372.

Zänker, H. \& Hennig, C. (2014). J. Contam. Hydrol. 157, 87-105.

Zänker, H., Weiss, S., Hennig, C., Brendler, V. \& Ikeda-Ohno, A. (2016). ChemistryOpen, 5, 174-182. 